\title{
DESEMPENHO DURANTE O ARMAZENAMENTO DE SEMENTES DE PEPINO SUBMETIDAS A DIFERENTES MÉTODOS DE SECAGEM ${ }^{1}$
}

\author{
PÂMELA GOMES NAKADA², JOÃO ALMIR OLIVEIRA³, LARISSA CORREIA DE MELO4, \\ ADRIANO ALVES DA SILVA ${ }^{5}$, PRISCILA ALVES DA SILVA², FABIANO JOSÉ PERINA ${ }^{6}$
}

\begin{abstract}
RESUMO - A secagem de sementes de pepino é etapa obrigatória no seu beneficiamento, bem como o armazenamento para conquistar mercados competitivos e melhores oportunidades de preços. Portanto, o objetivo com este trabalho foi o de avaliar o desempenho fisiológico e bioquímico durante a secagem e armazenamento de sementes de pepino. A cultivar utilizada foi o híbrido de pepino Ômega comercializado pela Agristar Ltda. As sementes foram lavadas e secadas em temperatura ambiente de $25{ }^{\circ} \mathrm{C}, 35^{\circ} \mathrm{C}$ e $45{ }^{\circ} \mathrm{C}$ até atingir grau de umidade de $7 \%$. As sementes foram embaladas em sacos de papel multifoliado e armazenadas em condições de ambiente não controlado. As avaliações da qualidade foram realizadas aos $0,3,6,9$ e 12 meses pelos testes de germinação, primeira contagem, condutividade elétrica e emergência de plântulas em bandeja. Avaliaram também as atividades enzimáticas de superóxido dismutase, catalase, esterase, lipoxigenase, isocitrato liase e proteína LEA, e por fim o teste de sanidade. A secagem de sementes de pepino, em temperatura ambiente, e a $35^{\circ} \mathrm{C}$ resulta em sementes de melhor qualidade. Ocorre redução da qualidade fisiológica das sementes e da atividade da proteína LEA a partir de seis meses de armazenamento, independente da temperatura de secagem.
\end{abstract}

Termos para indexação: Cucumis sativus, qualidade fisiológica, eletroforese.

\section{PERFORMANCE DURING STORAGE OF CUCUMBER SEEDS UNDER DIFFERENT METHODS OF DRYING}

\begin{abstract}
The drying of seeds of cucumber is a compulsory stage in his improvement, as well as the storage to conquer competitive markets and better opportunities of prices. So the objective with this work valued the physiologic and biochemical performance during the drying and storage of seeds of cucumber. Cultivating used was the hybrid of cucumber Ômega marketed by the Agristar Ltda. The seeds were washed and dried at room temperature $25{ }^{\circ} \mathrm{C}, 35{ }^{\circ} \mathrm{C}$ and $45{ }^{\circ} \mathrm{C}$, following the storage in conditions ambient. The physiologic quality was valued through the germination test, first counting, conductivity electric and seedlings emergence. Also there was done sanitary analysis, evaluation of the activity of enzymes from the superoxide dismutase, catalase, esterase, lipoxigenase, isocitrato liase and LEA protein, and finally the analysis of images through ray X. The drying of seeds
\end{abstract}

\begin{abstract}
${ }^{1}$ Submetido em 06/08/2009. Aceito para publicação em 20/04/2010. Trabalho financiado pela Fundação de Amparo a Pesquisa do Estado de Minas Gerais (FAPEMIG) e apresentado como parte da dissertação de mestrado do primeiro autor.
\end{abstract}

${ }^{2}$ Mestre pela Universidade Federal de Lavras (UFLA) - Caixa Postal 37, CEP: 37200-000, Lavras, MG; e-mail: pamnakada@yahoo.com.br.

${ }^{3}$ Prof. Dr., UFLA, Caixa Postal 37, CEP: 37200-000, Lavras, MG; e-mail jalmir@dag.ufla.br.
${ }^{4}$ Graduada em agronomia, UFLA, Caixa Postal 37, CEP: 37200-000, Lavras, MG; e-mail: larissamelo_agronomia@hotmail.com.

${ }^{5}$ Doutorando, UFLA, Caixa Postal 37, CEP: 37200-000, Lavras, MG; e-mail: adrianoas@msn.com.

${ }^{6}$ Mestrando, UFLA, Caixa Postal 37, CEP: 37200-000, Lavras, MG; e-mail: perinafj@gmail.com. 
of cucumber, in ambient temperature, and to $35^{\circ} \mathrm{C}$ turns in seeds of better quality. LEA takes place reduction of the quality of the seeds and of the activity of the protein from six months of storage independent of the method of drying.

Index terms: Cucumis sativus, quality physiological, electrophoresis.

\section{INTRODUÇÃO}

Atualmente as hortaliças têm ocupado maior espaço nas mesas dos brasileiros. Dessa forma, comercializar esse alimento tem se tornado uma atividade altamente lucrativa e, portanto um negócio importantíssimo na economia agrícola. Apesar do pequeno índice de consumo, da ordem de $40 \mathrm{~kg}$ per capto.ano ${ }^{-1}$, há expectativa de duplicação desse índice para os próximos anos (Diniz, 2005), o que justifica a necessidade de aumentar a produção de sementes.

Para a obtenção do produto com qualidade, dentre outros fatores, é necessário uma população adequada e uniforme de plantas no campo. Entretanto, o sucesso está condicionado à utilização de sementes de qualidade. Essa característica é o somatório dos atributos genéticos, físicos, fisiológicos e sanitários que afetam a sua capacidade de originar plantas de alta produtividade (Popinigis, 1985). Atualmente se reconhece que o vigor compreende um conjunto de características que determinam o potencial fisiológico, o qual é influenciado pelas condições de ambiente e manejo durante as etapas de pré e pós-colheita (Marcos Filho, 2005).

O pepino (Cucumis sativus), por ser um fruto carnoso, apresenta sementes com grau de umidade consideravelmente elevado, no momento da colheita. Portanto, não se deve retardar o processo de secagem dessas sementes devido aos efeitos de uma possível fermentação, cujos produtos desse processo podem acarretar danos imediatos.

Christ et al. (1997) relataram que a temperatura que danifica uma semente pode variar de acordo com a espécie e o seu teor de água inicial. Assim, Toledo e Marcos Filho (1977) já citavam que para um teor de água em sementes acima de $18 \%$ base úmida (bu), a temperatura máxima de secagem fosse de $32{ }^{\circ} \mathrm{C}$, para teor entre 10 e $18 \%$ (bu) a temperatura de $38{ }^{\circ} \mathrm{C}$, e quando fosse inferior a $10 \%$ (bu), de $43{ }^{\circ} \mathrm{C}$.

Os primeiros danos de secagem estão relacionados com a ruptura da membrana com posterior aumento da condutividade elétrica e lixiviação de açúcares (Chen e
Burris, 1990). Roberts (1981) relatou que a maioria dos sistemas subcelulares das sementes, incluindo os genes podem ser danificados por esse processo, principalmente quando o processo for executado de forma errônea sem levar em consideração o teor de água inicial, a temperatura, o método de secagem e a velocidade do processo. A secagem rápida danifica o sistema de membrana, sendo necessário mais tempo para os reparos de reidratação.

O agronegócio sementes de olerícolas é um setor de grande rentabilidade, principalmente de sementes híbridas devido ao custo elevado inserido no processo de produção. Utilizar de mecanismos para manter estoque regulador é a melhor opção para conseguir melhores preços de mercado. Sendo assim o armazenamento torna-se uma etapa de grande importância no programa de produção de sementes. De acordo com Pereira et al. (1994), a principal preocupação durante o período de armazenamento é a preservação da qualidade das sementes, minimizando a velocidade do processo de deterioração. Esse processo é influenciado pelas condições fisiológicas iniciais das sementes, pela localização e severidade dos danos físicos, pelas condições do armazenamento (grau de umidade e temperatura), pelo tipo e a incidência de patógenos e pela atuação conjunta desses fatores podendo proporcionar diferenças de comportamento entre lotes de sementes armazenadas.

Atualmente são escassos estudos na literatura em relação à secagem e armazenamento de sementes olerícolas; comumente são informações já estudadas e detidas por parte das empresas produtoras de sementes.

Para tanto, o objetivo nesta pesquisa foi avaliar o desempenho fisiológico e bioquímico de sementes de pepino durante a secagem e armazenamento.

\section{MATERIAL E MÉTODOS}

O experimento foi realizado na Hortiagro (empresa produtora de sementes de hortaliças), localizada próxima à cidade de Ijaci-MG e no Laboratório Central de Sementes da Universidade Federal de Lavras (UFLA) no período 
de fevereiro de 2007 a julho de 2008, com sementes de pepino (Cucumis sativus) híbrido Ômega, tipo caipira, comercializado pela Agristar do Brasil Ltda., com ciclo de 50-60 dias, que tem planta vigorosa e ginoica.

As sementes das linhagens foram plantadas em bandejas de isopor contendo o substrato plantimax com adubação em casa de vegetação. Após 20 dias da semeadura as mudas foram transplantadas, num espaçamento de $1,20 \times 0,40 \mathrm{~m}$, em uma proporção de três fêmeas para cada macho, sendo transplantadas com diferença de oito dias, iniciado pela linhagem fêmea.

Os frutos de pepino foram colhidos aos 45 dias após a antese e permaneceram em repouso por um dia. As sementes foram extraídas mecanicamente e colocadas para fermentar por dois dias sob temperatura ambiente, afim de eliminar a mucilagem envolvente. Após, foram lavadas com água corrente. As sementes foram submetidas a diferentes temperaturas de secagem, secagem a $25{ }^{\circ} \mathrm{C}$ sob mesa com circulação de ar forçado e duas secagens artificiais utilizando protótipos de secador construídos de acordo com Navratil e Burris (1982), com temperaturas de 35 e $45{ }^{\circ} \mathrm{C}$, até que se atingisse aproximadamente grau de umidade de 7\%. Cada tratamento foi dividido em cinco subamostras para serem embaladas em saco de papel multifoliado e, armazenadas sob condições não controladas por 12 meses, onde as médias de temperatura e umidade relativa do ar encontram-se na Figura 1, e sua qualidade fisiológica, bioquímica e sanitária foi avaliada a cada três meses, utilizando os seguintes testes:

Germinação: foram utilizadas quatro subamostras de 50 sementes, por tratamento, em substrato de papel, tipo "Germitest", na forma de rolo, à temperatura de $25^{\circ} \mathrm{C}$. A quantidade de água adicionada foi de 2,5 vezes a massa do papel seco, visando umedecimento adequado e uniformização do teste. As contagens foram realizadas no quarto e oitavo dia após a montagem do teste, sendo computado o percentual de plântulas normais, segundo as Regras para Análise de Sementes - RAS (Brasil, 1992). Primeira contagem: foi realizada conjuntamente ao teste de germinação computando-se o percentual de plântulas normais no quarto dia após a montagem do teste. Emergência de plântulas em bandeja: a semeadura foi realizada em bandejas de plástico contendo, como substrato, solo e areia, na proporção 1:2. Foram utilizadas quatro subamostras de 50 sementes portratamentoe, após a semeadura, asbandejasforam mantidas em câmara de crescimento vegetal, à temperatura de $25{ }^{\circ} \mathrm{C}$, em regime alternado de luz e escuro (12 horas). A contagem das plântulas normais foi iniciada quando houve a emergência da primeira plântula, realizando-se contagem diária até sua estabilização. O índice foi calculado utilizandose a fórmula de Maguire (1962). O estande final foi obtido aos 15 dias após a semeadura, computando-se a porcentagem de plântulas normais emergidas. Condutividade elétrica: foi realizado o teste de massa com quatro subamostras de 50 sementes por tratamento. As sementes foram pesadas com precisão de duas casas decimais, e em seguida, colocadas em copos de plástico com $75 \mathrm{~mL}$ de água destilada. Após 24 horas de embebição sob temperatura de $25{ }^{\circ} \mathrm{C}$, a condutividade elétrica foi determinada com auxílio de condutivímetro Digimed modelo CD 21, com os resultados expressos em $\mu \mathrm{S} . \mathrm{cm}^{-1} \cdot \mathrm{g}^{-1}$, de acordo com o método descrito por Vieira (1994). Sanidade: utilizou-se o método do papel filtro ("Blotter test") segundo as RAS (Brasil, 1992). Foram analisadas oito subamostras de 25 sementes para cada tratamento. As placas foram mantidas em câmara de incubação por 7 dias, sob regime alternado de luz e escuro por 12 horas, a $20{ }^{\circ} \mathrm{C}$. Decorrido esse período, procedeu-se a avaliação dos fungos, utilizando-se microscópio esteroscópico. Eletroforese dos perfis isoenzimáticos: as sementes de cada época de armazenamento foram maceradas, juntamente com polivinilpirrolidona e nitrogênio líquido, em cadinhos de porcelana. Desse material foram pesados 100 mg, para análise de cada enzima, colocado em eppendorf onde foram adicionados $250 \mu \mathrm{L}$ de tampão de extração (Tris HCL $0,2 \mathrm{M}, \mathrm{pH}: 8,0)$ e $0,1 \%$ de $\beta$-mercaptaenol. Esses permaneceram por toda a noite e no dia seguinte foram centrifugados a $14000 \mathrm{xg}$ por 30 minutos, a $4{ }^{\circ} \mathrm{C}$. Do sobrenadante, foram retirados $50 \mu \mathrm{L}$ com posterior aplicação em gel de poliacrilamida 7,5\% (gel separador) e 4,5\% (gel concentrador). A corrida eletroforética foi submetida à voltagem constante de $150 \mathrm{~V}$ por aproximadamente seis horas. Após esse período, os géis foram revelados para as enzimas catalase, superóxido dismutase, esterase, lipoxigenase, seguindo metodologia descrita por Alfenas (2006). Análise de proteínas resistentes ao calor: as sementes foram maceradas em cadinhos na presença de nitrogênio líquido, e adicionado tampão de extração descrito por Alfenas (1998), na proporção de 10 partes de tampão para 1 de amostra. As amostras foram centrifugadas a $16.000 \mathrm{xg}$ por 30 minutos, a $4{ }^{\circ} \mathrm{C}$. O sobrenadante foi separado e incubado em banhomaria a $85{ }^{\circ} \mathrm{C}$, por 10 minutos. Em seguida repetiu-se a centrifugação como descrito anteriormente, recolheu-se o sobrenadante e se procedeu à corrida eletroforética (Alfenas, 2006). A coloração dos géis foi feita utilizando-se solução de Coomassie Blue $0,05 \%$ por 12 horas e solução de ácido acético $10 \%$ para descoloração até visualização das bandas (Alfenas et al., 1991). 


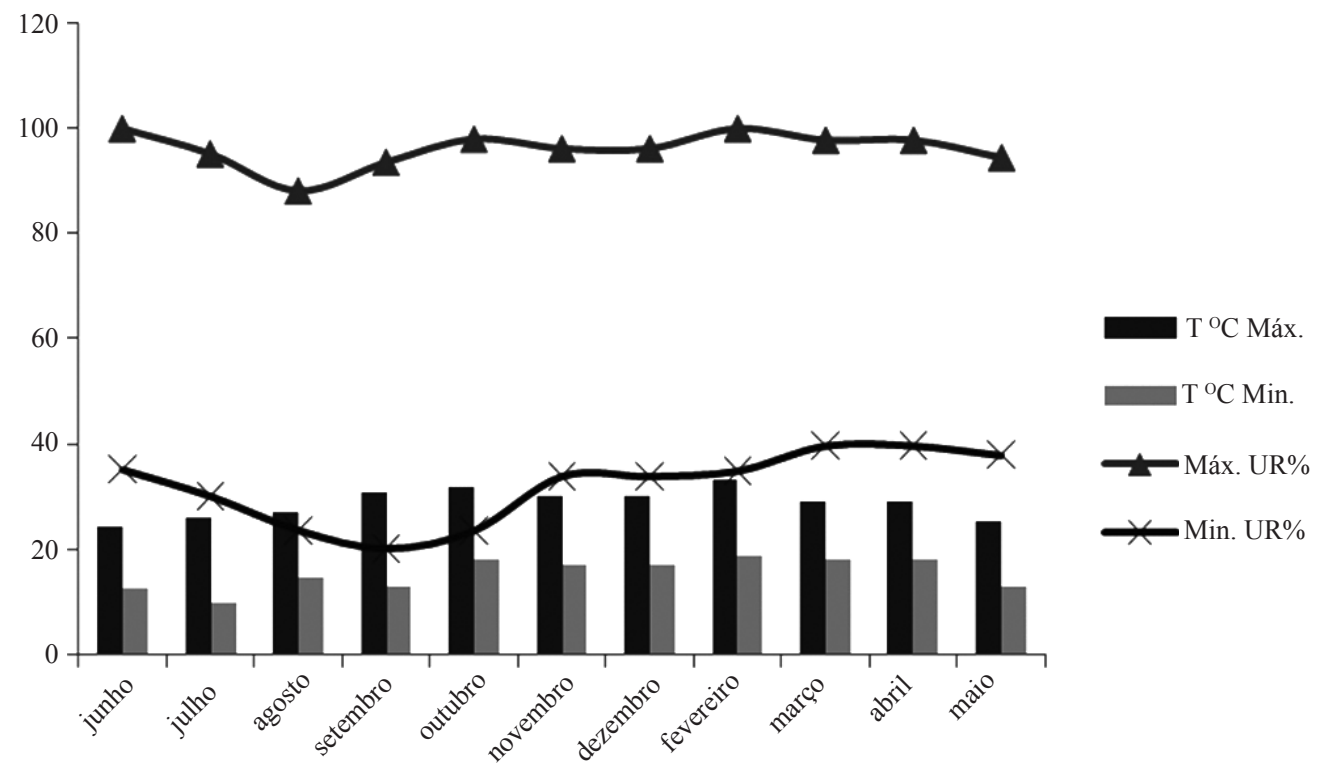

FIGURA 1. Temperatura e umidade relativa do ar ao longo do armazenamento em condições ambiente.

Delineamento experimental e análise estatística: utilizou-se delineamento experimental inteiramente casualizado com quatro repetições, arranjados em esquema fatorial $(3 \times 5)$, constituindo o primeiro fator temperaturas de secagem das sementes (temperatura ambiente, $35{ }^{\circ} \mathrm{C}$ e $45^{\circ} \mathrm{C}$ ), e no segundo, os cinco períodos de armazenamento $(0,3,6,9$ e 12 meses $)$. Para os testes de sanidade, eletroforese dos perfis isoenzimaticos e quantificação de proteína não foram realizadas análises estatísticas dos dados. Para a análise dos dados foi realizado estudo de regressão para o efeito quantitativo e teste de Tukey a $5 \%$ para comparação das médias, quando os efeitos qualitativos foram significativos.

\section{RESULTADOS E DISCUSSÃO}

Ocorreu efeito significativo para os dados de porcentagem de germinação somente para a época de armazenamento. Pode-se verificar que até aproximadamente os quatro meses de armazenamento (Figura 2) houve pequeno incremento da porcentagem de sementes germinadas com posterior redução gradativa até os doze meses de armazenamento, embora permanecendo com alto percentual de germinação (94\%).

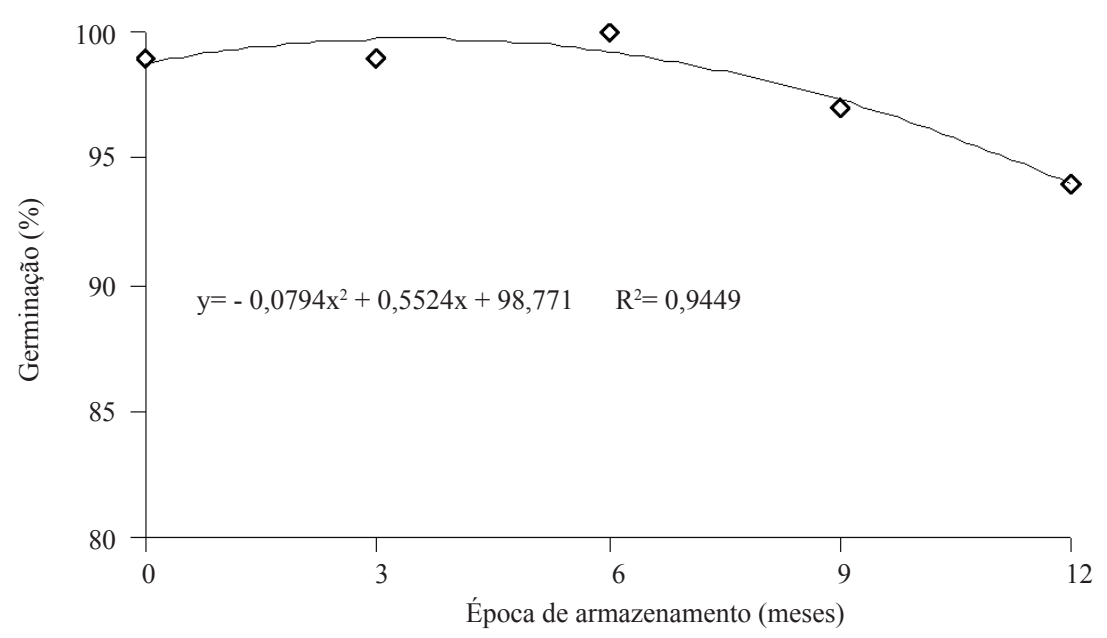

FIGURA 2. Porcentagem de germinação de sementes de pepino ao longo do armazenamento. 
Com relação ao vigor, para todas as variáveis, houve comportamento semelhante ao ocorrido com a porcentagem de germinação. Na primeira contagem de germinação (Figura 3A), realizada no quarto dia após a semeadura, verificou-se efeito significativo apenas para época de armazenamento das sementes. Observou-se que após, aproximadamente, quatro meses de armazenamento das sementes, houve queda gradativa na primeira contagem do teste de germinação até o final do armazenamento. No

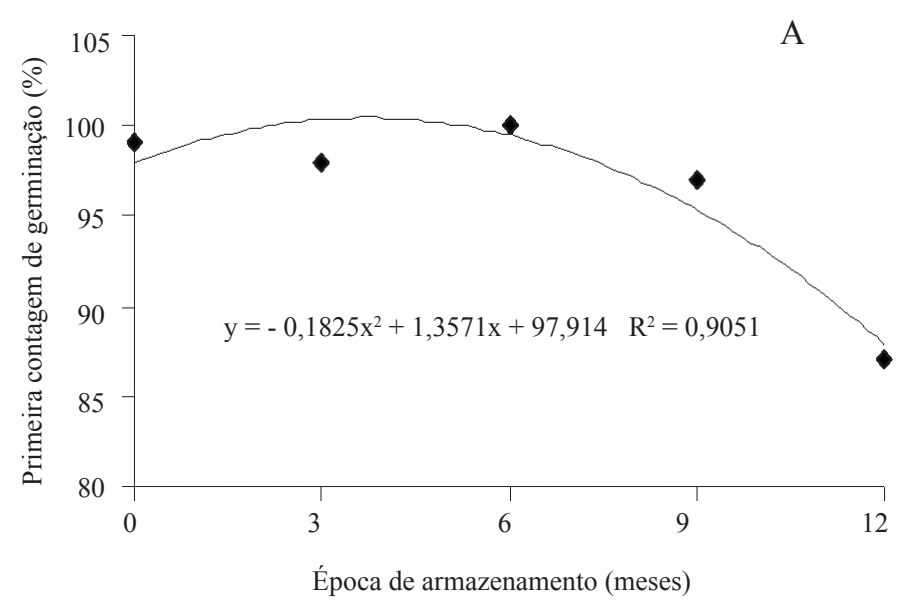

início do armazenamento, a porcentagem de germinação na primeira contagem foi próxima de $100 \%$, no entanto, aos 12 meses reduziu para $87 \%$. Também Camargo e Carvalho (2008) verificaram redução da porcentagem de germinação na primeira contagem, em sementes de milho doce embaladas em papel e armazenadas em ambiente natural, a partir dos seis meses de armazenamento, ocorrendo efeito acentuado ao final do armazenamento, 18 meses.

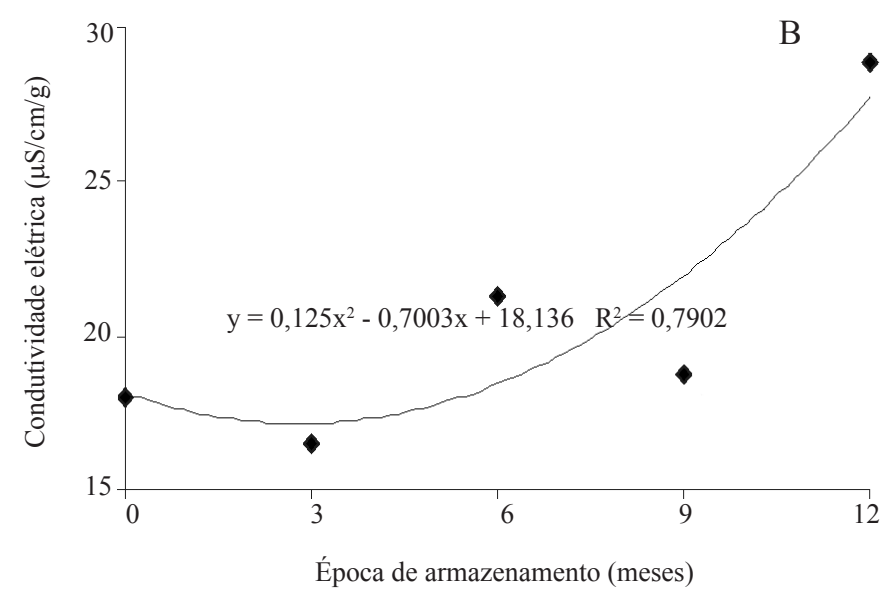

\section{FIGURA 3. (A) Primeira contagem de germinação e (B) condutividade elétrica de sementes de pepino ao longo do armazenamento.}

Ao analisar os dados do teste de condutividade elétrica, evidenciou-se significância para os efeitos individuais da época de armazenamento e das diferentes temperaturas de secagem (Tabela 1). Observou-se efeito significativo apenas para o período de nove meses de armazenamento, onde foi possível a distinção das temperaturas de secagem. Ocorreu destaque para as sementes secadas ao ambiente a qual não diferiu estatisticamente das sementes secadas à temperatura de $35{ }^{\circ} \mathrm{C}$, representando melhor reorganização no sistema de membranas após a embebição durante o processo de germinação. Isto se deve ao tempo gasto, na secagem, para atingir teor de água de aproximadamente $7 \%$. As sementes secadas à temperatura ambiente atingiram esse teor em um período de 24 horas. Já para sementes secas a temperatura de 35 e $45{ }^{\circ} \mathrm{C}$ foram gastos seis e quatro horas, respectivamente. Durante o processo de secagem mais rápido, com temperatura mais elevada, a $45^{\circ} \mathrm{C}$, pode ter ocorrido algum dano nos sistemas de membranas, diminuindo a capacidade de restabelecimento da organização das membranas celulares durante a embebição, e conseqüentemente, liberando maior quantidade de solutos para o meio (Rosa et al., 2000). De acordo com Christ et al. (1997), quanto maior for a temperatura, maior será a velocidade de secagem e consequentemente maiores serão os danos ocorridos.

Verificou-se menor lixiviação de solutos até aproximadamente o terceiro mês de armazenamento (Figura 3B). Os resultados obtidos por esse teste evidenciaram aumento progressivo das leituras com o decorrer do período de armazenamento, indicando deterioração dos sistemas de membranas, diminuindo a velocidade de reestruturação das mesmas, com conseqüente perda do vigor ao longo do armazenamento (Marcos Filho, 2005). Além disso, segundo Santos et al. (2005), a exsudação dos constituintes celurares está diretamente associada com a perda de vigor, e que, além da causa citada por Marcos Filho (2005), pode haver descompartimentalização dos constituintes celulares podendo constituir excelente substrato para o desenvolvimento de microrganismos. Esse mesmo autor, trabalhando com variedades de sementes de feijão, verificou o mesmo comportamento ao longo do armazenamento para os diversos materiais. 
TABELA 1. Condutividade elétrica e índice de velocidade de emergência de sementes de pepino ao longo do armazenamento secadas através de diferentes métodos e temperaturas.

\begin{tabular}{cccccc}
\hline \multirow{2}{*}{ Secagem } & \multicolumn{5}{c}{ Período de armazenamento (meses) } \\
\cline { 2 - 5 } & 0 & 3 & 6 & 9 & 12 \\
\hline ambiente & $14,6 \mathrm{a}^{*}$ & $15,0 \mathrm{a}$ & $20,2 \mathrm{a}$ & $14,5 \mathrm{a}$ & $26,7 \mathrm{a}$ \\
$35^{\circ} \mathrm{C}$ & $19,9 \mathrm{a}$ & $17,6 \mathrm{a}$ & $19,9 \mathrm{a}$ & $18,5 \mathrm{ab}$ & $32,3 \mathrm{a}$ \\
$45^{\circ} \mathrm{C}$ & $19,4 \mathrm{a}$ & $16,9 \mathrm{a}$ & $23,8 \mathrm{a}$ & $23,3 \mathrm{~b}$ & $27,6 \mathrm{a}$ \\
\hline & & ------- -́ndice de velocidade de emergência------- & $8,8 \mathrm{a}$ \\
\hline ambiente & $9,7 \mathrm{a} *$ & $11,1 \mathrm{a}$ & $12,5 \mathrm{a}$ & $11,0 \mathrm{a}$ & $8,4 \mathrm{a}$ \\
$35^{\circ} \mathrm{C}$ & $8,7 \mathrm{a}$ & $11,0 \mathrm{ab}$ & $12,7 \mathrm{a}$ & $12,0 \mathrm{a}$ & $8,4 \mathrm{a}$ \\
$45^{\circ} \mathrm{C}$ & $9,0 \mathrm{a}$ & $10,0 \mathrm{~b}$ & $12,6 \mathrm{a}$ & $11,2 \mathrm{a}$ & \\
\hline
\end{tabular}

*Médias seguidas por mesma letra na coluna não diferem estatisticamente pelo teste de Tukey a $5 \%$ de probabilidade

Torres (2005), ao avaliar a qualidade de sementes de melancia armazenadas em condições ambiente e câmara fria, por 12 meses, verificou aumento nas leituras da condutividade elétrica a partir do oitavo mês, destacando o processo deteriorativo.

Observou-se pelos resultados do teste de condutividade bastante coerência com os resultados do teste de germinação e primeira contagem de germinação, ou seja, na medida que aumentou a lixiviação houve redução no percentual de plântulas normais.

Para o índice de velocidade de emergência (IVE) foi constatado o efeito significativo da interação entre as diferentes temperaturas de secagem e época de

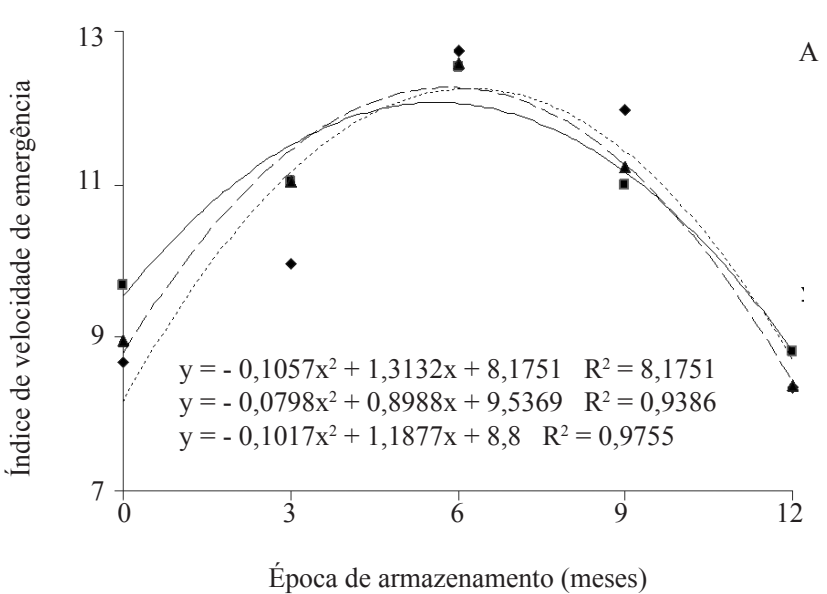

armazenamento. No início do armazenamento (Figura 4A), o índice de velocidade de emergência das sementes submetidas à temperatura de secagem de $35^{\circ} \mathrm{C}$ foi superior aquelas submetidas à temperatura de $45{ }^{\circ} \mathrm{C}$ e ambiente. Para essa variável houve comportamento semelhante ao observado nas anteriores, diferindo apenas com relação ao tempo de armazenamento, onde houve redução desse índice a partir de aproximadamente seis meses. $\mathrm{Na}$ Tabela 1 verifica-se diferença significativa, entre as temperaturas de secagem, apenas na época de três meses de armazenamento onde houve desempenho superior das sementes secadas no ambiente a qual não diferiu das sementes secadas sob $35^{\circ} \mathrm{C}$.
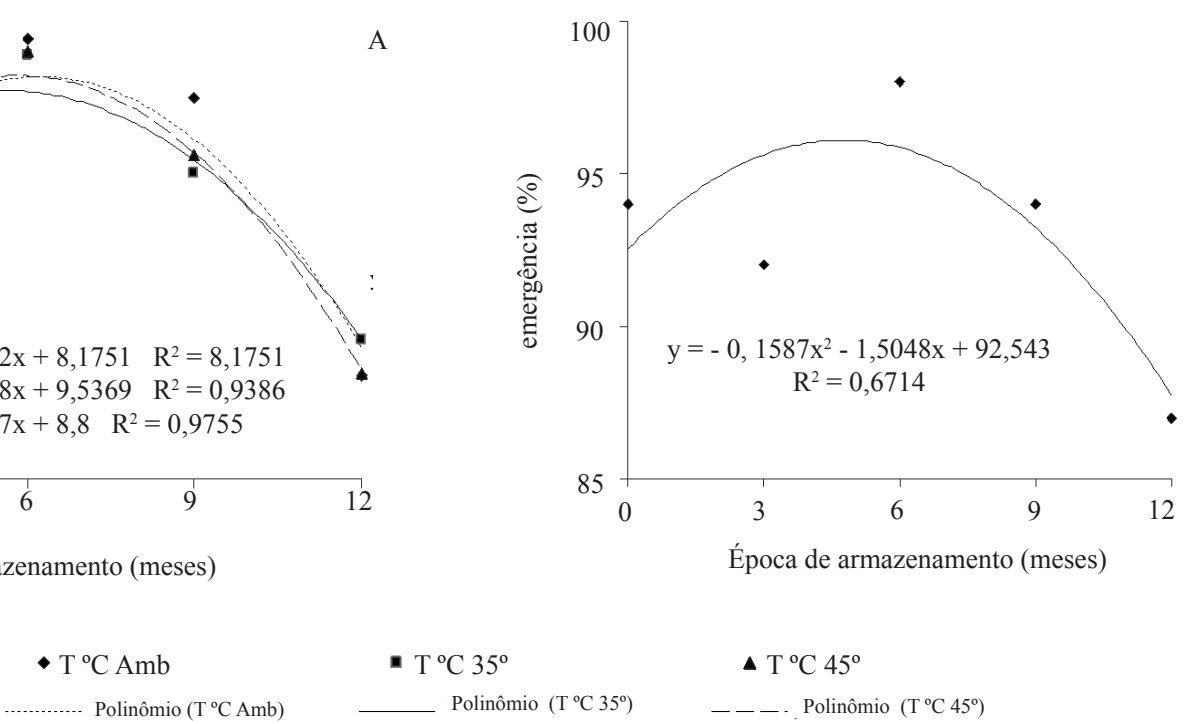

FIGURA 4. Índice de velocidade de emergência e percentual de plântulas de pepino emergidas de sementes secadas em diferentes métodos e avaliadas ao longo do armazenamento. 
Resultados semelhantes foram verificados por Veiga (2007), ao avaliar sementes de cafeeiro submetidas a diferentes métodos de secagem, quando observou que a partir do quarto mês de armazenamento, os valores de IVE foram reduzidos substancialmente. Esse autor justificou essa queda de qualidade à presença de radicais livres em sementes sensíveis à dessecação, pois durante o processo de secagem, há acúmulo de radicais livres. Vale ressaltar que a semente de pepino tolera a dessecação, e apesar disso, ao longo do armazenamento pode haver a formação desses radicais livres, contribuindo para o processo de deterioração.

Ao analisar o estande final (Figura 4B), foi verificada a ocorrência de efeito significativo somente para a época de armazenamento. É possível observar que até aproximadamente o quinto mês de armazenamento, houve aumento na porcentagem de emergência de plântulas, e após esse período, houve queda gradativa dessa porcentagem até o final do armazenamento, resultados semelhantes aos obtidos para índice de velocidade de emergência. Em contrapartida, Torres et al. (2002) observaram que sementes de maxixe, pertencente a mesma família do pepino, armazenadas em diferentes locais e embalagens, por período de 12 meses, não apresentaram perda da qualidade para qualquer tratamento estudado.

Para todas as características avaliadas, verificou-se desempenho semelhante, com acréscimo gradativo da qualidade até certo período do armazenamento, e posterior redução. Provavelmente esse fato pode estar associado à dormência primária presente em sementes de pepino, que foi superada logo no início do armazenamento, quando já se iniciou o processo deteriorativo. Barbedo et al. (1999) também verificaram em seus estudos, com sementes de pepino armazenadas, algum problema com a germinação inicial ao comparar com a porcentagem de germinação do segundo mês de armazenamento, suspeitando de uma possível dormência.

Essa provável dormência foi sendo reduzida até próximo de cinco meses, quando então as sementes foram perdendo o vigor, conforme já verificado nos testes de primeira contagem e germinação. Thomazelli et al. (1992) também verificaram algum tipo de dormência em sementes de cebola no início do armazenamento, a qual foi eliminada gradativamente com o passar do tempo, paralelo a isso ocorreu aumento do vigor, atingindo valores máximos e posterior redução da qualidade, caracterizando o processo deteriorativo.

$\mathrm{Na}$ avaliação sanitária das sementes foi observada a ocorrência de sete gêneros de fungos: Aspergillus, Penicillium, Fusarium, Cladosporium, Phoma, Epicocum e Nigrospora. Os três últimos gêneros foram detectados de forma esporádica, por isso não foram discutidos no presente trabalho.

Aspergillus e Penicillium são fungos de armazenamento de importância, não só para o pepino mas também para várias outras espécies. Estes fungos podem ocasionar danos parciais ou totais com relação à viabilidade. Pela Figura 5 verifica-se maior incidência em sementes secadas a 35 e $45{ }^{\circ} \mathrm{C}$ de ambos os patógenos, predominando a presença do Aspergillus até o fim do armazenamento apesar de ter ocorrido redução da incidência. Mesmo assim pode-se inferir a atuação desses patógenos na deterioração das sementes. Pádua et al. (2002), ao avaliarem a qualidade sanitária de sementes de algodão, verificaram a presença desses dois fungos, e além disso detectaram correlação altamente significativa concluindo que ambos podem ocorrer em associação, sendo favorecidos pelas mesmas condições ambientais, causando deterioração nas sementes ao longo do armazenamento.
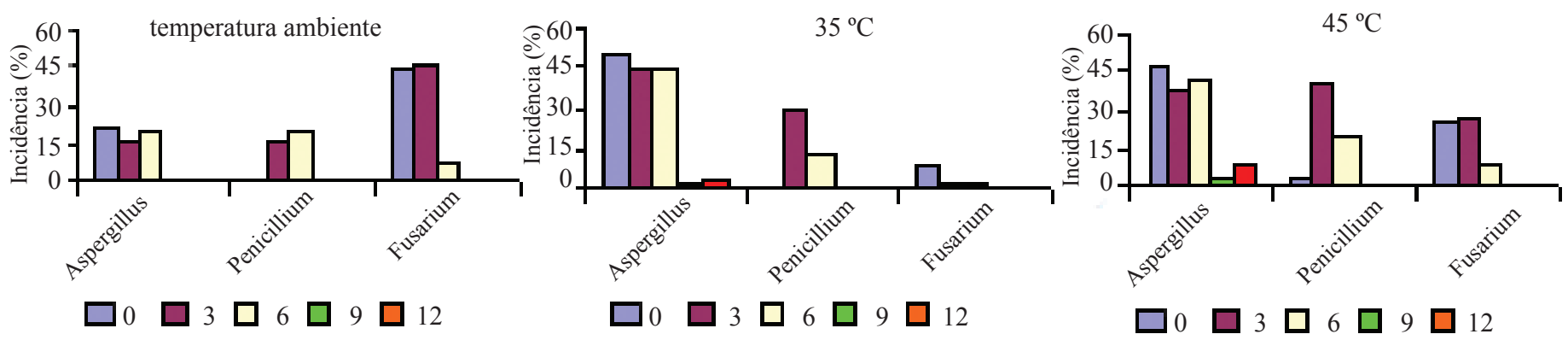

FIGURA 5. Incidência (\%) de Aspergillus, Penicillium e Fusarium em sementes de pepino secadas em diferentes métodos e avaliadas ao longo do armazenamento. 
Fusarium é classificado como fungo de campo, e pode causar grandes prejuízos quando então retornam ao campo ocasionando murcha e podridões de plântulas, com perdas expressivas. Ao longo do armazenamento a tendência foi reduzir-se (Figura 4), onde os níveis de incidência se sobressaíram no início do armazenamento, equiparando-se até os três meses, ocorrendo redução da incidência com o passar do tempo em todos os tipos de secagem.

Pelos resultados da análise eletroforética (Figura 6), verificou-se maior atividade da proteína LEA (Figura 6A) aos zero e três meses de armazenamento, independente do tipo de secagem, comprovado pelos resultados da germinação. É sabido que essas proteínas são formadas nas fases finais de desenvolvimento de sementes ortodoxas (Veiga et al., 2007), bem como do pepino. Bray (1993) relatou que as LEAs podem ligar íons e água, minimizando os danos de secagem. Blackman et al. (1991) verificaram que, à medida que proteínas LEA acumulam-se nas sementes de soja, menores são os valores de lixiviação de solutos, após secagem. Contudo, as LEAs em sementes, além de desempenhar tolerância à dessecação, também promovem estabilização e estruturação do sistema de membrana (Blackman et al., 1991).
(A)

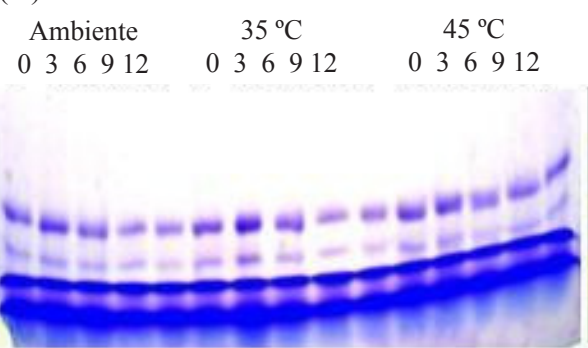

(D) Ambiente $35^{\circ} \mathrm{C}$ 0336912
(B) Ambiente

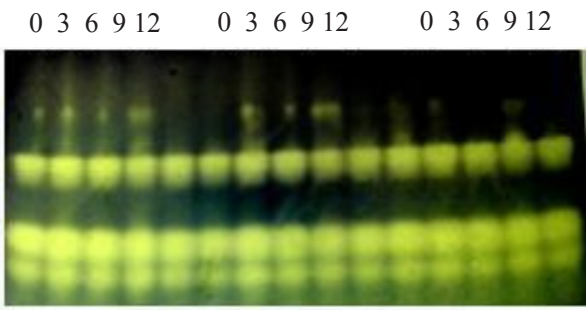

(E) $45^{\circ} \mathrm{C}$ 0366912
Ambiente

0336912
(C)
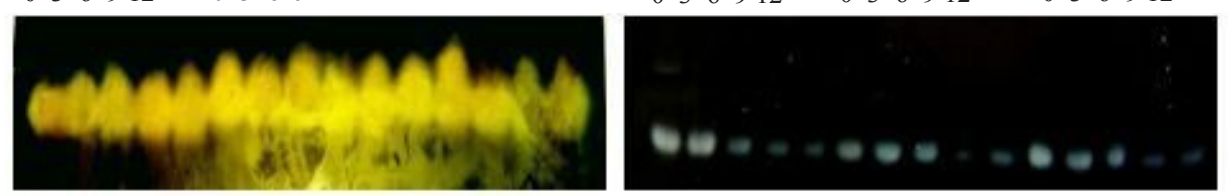

FIGURA 6. Atividade enzimática das proteínas LEA (A), superóxido dismutase (B), esterase (C), catalase (D) e lipoxigenase (E) em sementes de pepino secadas em diferentes métodos e avaliadas ao longo do armazenamento.

Utilizando-se de marcadores moleculares, é possível a associação de algumas enzimas que caracterizam o processo deteriorativo. A esterase (Figura 6C) teve comportamento semelhante nas sementes secadas à temperatura ambiente e à $35^{\circ} \mathrm{C}$ havendo maior atividade até os seis meses de armazenamento. Na temperatura de $45{ }^{\circ} \mathrm{C}$ ocorreu aumento gradativo da atividade enzimática a medida que se avançou no tempo de armazenamento. Sabe-se que a esterase além de caracterizar sementes em deterioração, pode auxiliar no processo germinativo. Segundo Aung e McDonald (1995), as esterases são o mais importante grupo de enzimas na germinação de amendoim. Esse grande grupo de enzimas hidrolíticas liberam ácidos graxos dos lipídeos, os quais são usados na $\beta$-oxidação, como fonte de energia para os eventos germinativos. $\mathrm{O}$ pepino pertence à família das cucurbitáceas, o mesmo das abóboras, e segundo Sant'anna (2005) as sementes dessa espécie possuem $28,8 \%$ de lipídios, podendo-se considerar similaridade do material de reserva para a espécie em estudo.

Evidenciou-se alta atividade da lipoxigenase até o sexto mês de armazenamento das sementes secadas nos diferentes métodos (Figura 6E), com exceção das sementes secas no ambiente, que apresentaram alta atividade apenas até o terceiro mês. A lipoxigenase tem por função a peroxidação de lipídios, onde os das membranas estão mais propensos, pois possuem ampla superfície e predomínio de lipídios insaturados altamente sensíveis à degradação, o que pode provocar desequilíbrio da viscosidade e permeabilidade das membranas. Após sua atuação ocorre formação de radicais livres, que está relacionada com a deterioração das sementes (Wilson e McDonald, 1986). Entretanto, Oliveira et al. (2006) detectaram maior velocidade de emergência de plântulas 
de soja quando essa enzima esteve presente, auxiliando na mobilização de lipídios. Esse resultado se assemelha ao ocorrido no presente estudo, pois se verificou melhor desempenho das sementes até o período de seis meses de armazenamento onde também houve maior atividade da lipoxigenase.

Mecanismos de defesa em sementes são de extrema importância para conservação da qualidade fisiológica principalmente quando se tem por objetivo o seu armazenamento. A superóxido dismutase é a primeira dessa linha. Verificou-se a intensa atividade da superóxido dismutase (SOD) nas sementes que foram secadas em ambiente, praticamente para todas as épocas de armazenamento (Figura 6B). Essas sementes levaram 24 horas (velocidade de secagem 1,45\%/h) para atingirem teor de água de aproximadamente 7\%. Esse tempo gasto foi seis (velocidade de secagem $5,8 \% / \mathrm{h}$ ) e quatro (velocidade de secagem $8,75 \% / \mathrm{h}$ ) vezes maior ao comparar com sementes secadas a 35 e $45{ }^{\circ} \mathrm{C}$, respectivamente. Provavelmente esse maior tempo exposto à umidade tenha feito com que aumentasse o metabolismo e houvesse formação de radicais livres, ativando a superóxido dismutase como mecanismo protetor e removedor de forma ativa de oxigênio molecular. Essa enzima foi capaz de detectar diferenças sutis que não foram detectadas nos testes fisiológicos.

Após a atuação da SOD, ocorre a formação de peróxido de hidrogênio. Surge então a segunda enzima, a catalase, que irá atuar na proteção das sementes, pois a mesma tem a capacidade de transformar o peróxido em oxigênio e água (Taiz e Zeiger, 2004; Buchanan et al., 2005). Portanto, observou-se que houve maior atividade da catalase para sementes secadas no ambiente e $35^{\circ} \mathrm{C}$ (Figura 6D), ocorrendo aumento gradativo para a primeira, e comportamento homogêneo e elevado para a segunda. Esse resultado elucidou o que ocorre no armazenamento das sementes, ou seja, avanço no processo deteriorativo, e com isso a atuação do mecanismo de proteção.

Já para as sementes secadas a $45^{\circ} \mathrm{C}$ o padrão de banda dessa enzima teve um comportamento diferente quando comparado aos outros tratamentos, em que houve maior atividade até os três meses de armazenamento. Apesar da secagem não ter afetado as características fisiológicas, é possível que bioquimicamente tenha sido afetado pela alta temperatura de secagem $\left(45^{\circ} \mathrm{C}\right)$, efeito este revelado, principalmente, ao longo do armazenamento. Basavarajappa et al. (1991), ao estudarem os efeitos do envelhecimento em sementes de milho, verificaram que a intensidade das bandas da catalase diminuía com aumento do período de envelhecimento.

\section{CONCLUSÕES}

A secagem de sementes de pepino em temperatura ambiente e a $35{ }^{\circ} \mathrm{C}$ resulta em sementes de melhor qualidade.

Ocorre redução da qualidade fisiológica das sementes e da atividade da proteína LEA a partir de seis meses de armazenamento, independente do método de secagem.

As atividades das enzimas superóxido dismutase, catalase e lipoxigenase confirmam os resultados dos testes fisiológicos utilizados para avaliar a qualidade de sementes de pepino.

\section{REFERÊNCIAS}

ALFENAS, A.C. Eletroforese de isoenzimas e proteínas afins: fundamentos e aplicações em plantas e microorganismos. Viçosa: UFV, 1998. 574p.

ALFENAS, A.C. Eletroforese e marcadores bioquímicos em plantas e microrganismos. Viçosa: UFV, 2006. 627p.

ALFENAS, A.C. PETERS-ROBINSON, I.; BRUNE, W. Eletroforese de proteínas e isoenzimas de fungos e essências florestais. Viçosa: UFV, 1991. 242p.

AUNG, U.T.; McDONALD, M.B. Changes in esterase activity associated with peanut (Arachis hipogaea L.) seed deterioration. Seed Science and Technology, v.23, n.1, p.101-111, 1995.

BARBEDO, C.J. BARBEDO, A.S.C.; NAKAGAWA, J.; SATO. O. Efeito da idade e do repouso pós-colheita de frutos de pepino na semente armazenada. Pesquisa Agropecuária Brasileira, v.34, n.5, p.839-847, 1999.

BASAVARAJAPPA, B.S.; SHETTY, H.S.; PRAKASH, H.S. Membrane deterioration and other biochemical changes, associated with accelerated ageing of maize seeds. Seed Science and Technology, v.19, n.2, p.279-286, 1991.

BLACKMAN, S.A. WETTLAUFER, S.H.; OBENDORF, R. L.; LEOPOLD, A.C. Maturation proteins associated with desiccation tolerance in soybean. Plant Physiology, v.96, n.3, p.868-874, 1991.

BRASIL. Ministério da Agricultura e Reforma Agrária. Secretaria Nacional de Defesa Agropecuária. Departamento 
Nacional de Defesa Vegetal. Coordenação de Laboratório Vegetal. Regras para análise de sementes. Brasília, DF, 1992. 365p.

BRAY, E. Molecular responses to water deficit. Plant Physiology, v.103, n.4, p.1035-1040, 1993.

BUCHANAN, B.B.; GRUISSEM, W.; JONES, R. L. Biochemistry \& molecular biology of plants. American Society of Plant Physiologists: Rockville, Maryland, 2005. $451 \mathrm{p}$.

CAMARGO, R.; CARVALHO, M.L.M. Armazenamento a vácuo de semente de milho doce. Revista Brasileira de Sementes, v.30, n.1, p.131-139, 2008.

CHEN, Y.G.; BURRIS, J.S. Role of carbohydrate in desiccation tolerance and membrane behavior in maturing maize seed. Crop Science, v.30, n.3, p.971-975, 1990.

CHRIST, D.; CORREAA, P.C.; ALVARENGA, E.M. Efeito da temperatura e da umidade relativa do ar de secagem sobre a qualidade fisiológica de sementes de canola (Brassica napus L. var. oleifera Metzg.). Revista Brasileira de Sementes, v.19, n.2, p.150-154, 1997.

DINIZ,K.A.Incorporaçãodemicrorganismos,aminoácidos, micronutrientes e reguladores de crescimento em sementes de espécies olerícolas pela técnica de peliculização. 2005 . 71f. Dissertação (Mestrado em Fitotecnia) - Universidade Federal de Lavras, Lavras, MG.

MAGUIRE, J.D. Speed of germination-aid in selection and evaluation for seedling emergence and vigor. Crop Science, v.2, p.176-7, 1962.

MARCOS FILHO, J. Fisiologia de sementes de plantas cultivadas. Piracicaba: FEALQ, 2005. 495p.

NAVRATIL, R.J.; BURRIS, J.S Small-scalle dryer design. Agronomy Journal, v.74, p.159-161, 1982.

OLIVEIRA, D.A. et al. A. Lipoxigenases e teor de ácido linolênico relacionados à qualidade de sementes de soja. Revista Brasileira de Sementes, v.28, n.1, p.30-35, 2006.

PÁDUA, G.P.; VIEIRA, R.D.; BARBOSA, J.C. Desempenho de sementes de algodão tratadas quimicamente e armazenadas. Revista Brasileira de Sementes, v.24, n.1, p.212-219, 2002.

PEREIRA, G.F.A. et al. Fungos de armazenamento em lotes de sementes de soja descartados no estado de Minas Gerais na safra 1989/90. Revista Brasileira de Sementes, v.6, n.2, p.216-219, 1994.
POPINIGIS, F. Fisiologia da semente. Brasília, DF: AGIPLAN, 1985. 289 p.

ROBERTS, E.H. Physiology of ageing and its application to drying and storage. Seed Science and Technology, v.9, p.359-372, 1981.

ROSA, S.D.V.F.; et al. Eficácia do teste de condutividade elétrica para uso em estudos de danos de secagem em sementes de milho. Revista Brasileira de Sementes, v.22, n.1, p.54-63, 2000 .

SANT'ANNA, L.C. Avaliação da composição química da semente de abóbora (Cucurbita pepo) e do efeito do seu consumo sobre o dano oxidativo hepático de ratos (Rattus novergicus). 2005. 69f. (Dissertação de Mestrado) Universidade Federal de Santa Catarina, Florianópolis.

SANTOS, C.M.R.; MENEZES, N.L.; VILLELA, F.A.. Modificações fisiológicas e bioquímicas em sementes de feijão no armazenamento. Revista Brasileira de Sementes, v.27, n.1, p.104-114, 2005.

TAIZ, L.; ZEIGER, E. Plant physiology. Califórnia: Cummings, 2004. 565p.

THOMAZELLI, L.F. et al. Efeito do nitrogênio, fósforo e potássio na produção e qualidade de sementes de cebola. Revista Brasileira de Sementes, v.14, n.2, p.161-165, 1992.

TOLEDO, F.F.; MARCOS FILHO, J. Manual de sementes tecnologia da produção. São Paulo: Agronômica Ceres, 1977. $224 p$.

TORRES, S.B. et al. Qualidade de sementes de maxixe armazenadas em diferentes embalagens e ambientes. Ciência Agrotécnica, v.26, n.3, p.539-544, 2002.

TORRES, S.B. Qualidade de sementes de melancia armazenadas em diferentes embalagens e ambientes. Revista Ciência Agronômica, v.36, n.2, p.163-168, 2005.

VEIGA, A.D. et al. Tolerância de sementes de soja à dessecação. Ciência e Agrotecnologia, v.31, n.3, p.773-780, 2007.

VIEIRA, R.D. Teste de condutividade elétrica. In: VIEIRA, R.D.; CARVALHO, N.M. (Ed.). Testes de vigor em sementes. Jaboticabal: FUNEP, 1994. p.103-132.

WILSON JR, D.O.; MCDONALD JR, M.B. The lipid peroxidation model of seed ageing. Seed Science and Technology, v.14, n.2,p.269-300, 1986. 